\title{
Clinical Characteristics and Outcomes Among COVID-19 Hospitalized Patients with Chronic Conditions: A Retrospective Single-Center Study
}

This article was published in the following Dove Press journal: Journal of Multidisciplinary Healthcare

\author{
Ziyad Saeed Almalki (D) \\ Mohd Faiyaz Khan (D)' \\ Saja Almazrou (D) ${ }^{2}$ \\ Abdullah Salah Alanazi $\mathbb{D}^{3}$ \\ Mohammed Shahid Iqbal (D) \\ Abdulhadi Alqahtani (D) \\ Saleh Alghamdi $\mathbb{D}^{4}$ \\ Abdullah K Alahmari (iD) \\ 'Department of Clinical Pharmacy, \\ College of Pharmacy, Prince Sattam Bin \\ Abdulaziz University, Al-Kharj, Riyadh, \\ Saudi Arabia; ${ }^{2}$ Clinical Pharmacy \\ Department, College of Pharmacy, King \\ Saud University, Riyadh, Saudi Arabia; \\ ${ }^{3}$ Clinical Pharmacy Department, College \\ of Pharmacy, Jouf University, Sakaka, \\ Aljouf, Saudi Arabia; ${ }^{4}$ Clinical Research \\ Department, Research Center, King \\ Fahad Medical City, Riyadh, Saudi Arabia
}

Purpose: Evidence to date suggests that having chronic conditions increases the probability of severe illness from severe coronavirus disease 2019 (COVID-19). Thus, it is essential to identify the features of those patients. The purpose of this research was to identify the clinical characteristics and outcomes of COVID-19 patients with chronic conditions.

Patients and Methods: A retrospective cross-sectional single-center study was conducted using electronic medical records of hospitalized COVID-19 patients between March 1, 2020, and May 20, 2020. Patients' basic information, laboratory test, clinical data, medications, and outcome data have been extracted and compared among three groups: patients without chronic conditions, patients with one chronic condition, and patients with two or more chronic conditions. Chi-square, Fisher's exact test, Student's $t$-test, and the Mann-Whitney $U$-test were used. Results: The study population was 458 patients, with an average age of 38.8 years (standard deviation (SD) 12.8). There were 398 (86.9\%) males in the study population, most of them with one chronic condition. There were $14(14.3 \%)$ smokers, and the majority of them were among patients with two or more chronic conditions. Longer hospital stay and time in the intensive care unit (ICU), a higher probability of ICU admission, and the need for mechanical ventilation were identified among patients with two or more chronic conditions. Dyspnea, an increased level of platelet counts, and a reduction in hemoglobin levels were discovered among patients with two or more chronic conditions.

Conclusion: Patients with more chronic conditions were at higher risk of yielding poor clinical outcomes. Prevention and treatment of infections in these patients merit more attention.

Keywords: chronic conditions, clinical features, outcomes, coronavirus disease 2019

\section{Introduction}

In December 2019, a pneumonia cluster with unknown etiology was reported by the World Health Organization (WHO) in Wuhan, the sprawling capital of Central China's Hubei province. ${ }^{1}$ A distinctive coronavirus was subsequently isolated from patients, which led to the detection of a new beta-corona virus named "SARS coronavirus (SARS-CoV 2)," which caused coronavirus disease 2019 (COVID19). ${ }^{2,3}$ Within days, health authorities in China confirmed more cases, announced a virus outbreak, and linked its origin to the seafood market of Wuhan. ${ }^{4} \mathrm{Up}$ to the end of January 2020, other countries also started reporting COVID-19 cases. The WHO Emergency Committee subsequently laid down COVID-19 as an acute respiratory disease and declared it an international public health emergency. ${ }^{5}$
Correspondence: Ziyad Saeed Almalki Department of Clinical Pharmacy, College of Pharmacy, Prince Sattam Bin Abdulaziz University, Al-Kharj, Riyadh, Saudi Arabia

Tel +966 II 5886059

$\mathrm{Fax}+966$ II 5886000

Email z.almalki@psau.edu.sa

Journal of Multidisciplinary Healthcare 2020:13 1089-1097 
The Kingdom of Saudi Arabia (KSA) announced on 2 March 2020 the first COVID-19 case, and the first death was reported on the 24th of March 2020. Fortunately, the KSA has had previous experience managing a similar virus, Middle East respiratory syndrome coronavirus (MERS-CoV), since 2013. ${ }^{6}$ In response to COVID-19 infection prevention and control (IPC), KSA updated its standard protocol and requirements across the nation. ${ }^{7}$ Since then, the Ministry of Health has started 31 health centers in six regions for COVID19-infected patients that include around 8000 intensive care unit (ICU) beds and 80,000 hospital beds. ${ }^{8}$ In addition to this, 2200 beds have been assigned for isolation of quarantined and suspected cases. ${ }^{9}$ The different categories of beds are prepared due to the severity of symptoms of COVID-19.

Evidence to date suggests that having chronic conditions increases the risk of severe illness from COVID-19 that requires patients to be hospitalized, to be admitted to the ICU, and to be intubated. In addition, data exists regarding the vulnerability of patients who are taking immune suppressors to treat their inflammatory chronic conditions. They are more susceptible to infection by the COVID-19 and tend to develop more severe infections. ${ }^{10}$

In Saudi Arabia, a single study was conducted to assess clinical characteristics of COVID-19 patients. ${ }^{11}$ While the study provided a valuable look at the characteristics of COVID-19 patients in Saudi Arabia, it did not demonstrate the differences in clinical characteristics and the outcomes in terms of the number of chronic conditions.

Because the different symptoms and severity of COVID-19 in patients with or without chronic conditions remain to be characterized, it is essential to identify the clinical features of those patients. Furthermore, in the absence of treatment that is sufficiently effective for COVID-19, the findings of this study could assist in drugrepurposing and drug discovery phenomena. ${ }^{12}$ Therefore, the purpose of this research was to identify the clinical characteristics and outcomes of COVID-19 patients with chronic conditions. The study results could contribute to developing preventive strategies and management of those patients. In addition, results can help to improve patient resource allocation and risk-stratified care strategy in COVID-19 patients.

\section{Patients and Methods}

\section{Study Design}

A descriptive, non-experimental, cross-sectional study was conducted of hospitalized patients with COVID-19 between March 1, 2020, and May 20, 2020. We follow the guideline for cross-sectional analysis developed by STrengthening the Reporting of OBservational studies in Epidemiology (STROBE).

\section{Study Setting}

In the infectious disease center in Prince Mohammed bin Abdul Aziz hospital (PMAH) in Riyadh, we checked all adult patients diagnosed with COVID-19. The hospital is one of the major referral hospitals located east of Riyadh, and it spans an area of $105,000 \mathrm{~m}^{2}$ and has five floors and over 500 beds. The hospital was established with 120 beds for intensive care, 63 rooms for an emergency, 15 rooms for operations, a pavilion for radiology, and laboratories. Currently, the center of the study is one of the main healthcare centers in the Riyadh region that provides healthcare services to patients with COVID-19 who were transferred to this hospital.

\section{Study Population}

The research recruited adults, men and women of all ages with COVID-19 infection confirmed in the laboratory using real-time reverse transcriptase-polymerase chain reaction (RT-PCR). According to the number of chronic conditions that each patient had, the patients were categorized into three main groups: patients without chronic conditions, patients with one chronic condition, and patients with two or more chronic conditions. Chronic conditions were defined as conditions "that last 12 months or more and require ongoing medical attention or limit activities of daily living or both". ${ }^{13}$

\section{Data Source}

The medical records of all hospitalized patients were retrieved. For this study, records of patients with laboratory-confirmed Covid-19 is obtained by trained medical personnel. A patient's medical record consists of data on patients' basic information (age, gender, smoking status, and nationality), clinical characteristics including all existing chronic conditions, laboratory data, treatment, and outcomes. To achieve a good performance on data extraction, a well-designed and organized checklist was utilized to obtain information from patients' medical records. Clinical results were followed up to June 15, 2020. Data were collected as fully as possible in order to avoid a lack of data. 


\section{Variable Definitions}

The variable level of obesity was determined according to the body mass index (BMI). BMI was computed as weight $(\mathrm{kg}) /$ height $\left(\mathrm{m}^{2}\right)$, and a patient was classified as obese when BMI is $\geq 30$, as per the WHO weight classification. ${ }^{14}$ Other chronic conditions were identified according to whether the patients have had any of the following conditions: diabetes mellitus (defined as current use of diabetic-lowering medication associated with Hemoglobin Alc (HbAlc) levels $\geq 7 \%$ in accordance with the recommendations from the American Diabetes Association), ${ }^{15}$ hypertension [they are on current use of blood pressure-lowering medication associated with an average systolic blood pressure $\geq 140 \mathrm{~mm} \mathrm{Hg}$ and an average diastolic blood pressure $\geq 90 \mathrm{~mm} \mathrm{Hg}$; or an average systolic blood pressure $\geq 130 \mathrm{~mm} \mathrm{Hg}$ and an average diastolic blood pressure $\geq 80 \mathrm{~mm} \mathrm{Hg}$ (if they had a history of cardiovascular disease or diabetes mellitus)], ${ }^{16}$ asthma (a previous diagnosis of asthma), pneumonia (indication of pneumonia via Chest X-ray and CT findings examination), kidney disease (urinary albumin creatinine ratio (UACR) $\geq 30 \mathrm{mg} / \mathrm{g}$ and/or estimated glomerular filtration rate [eGFR] $<60 \mathrm{~mL} / \mathrm{min} / 1.73 \mathrm{~m}^{2}$ ), cardiovascular disease (a previous diagnosis of angina, myocardial infarction, stroke, or heart failure), cancer (a previous diagnoses of any type of cancers), psychiatric disease (a previous diagnoses of any type of psychiatric diseases), dyslipidemia (total cholesterol $\geq 200 \mathrm{mg} / \mathrm{dL}$, triglycerides $\geq 150 \mathrm{mg} / \mathrm{dL}$, Low-density lipoprotein cholesterol (LDL-C) $\geq 100 \mathrm{mg} /$ $\mathrm{dL}$, or high-density lipoprotein cholesterol (HDL-C) $\leq$ $40 \mathrm{mg} / \mathrm{dL}$ in males and $\leq 50 \mathrm{mg} / \mathrm{dL}$ in females), and thyroid disease (a previous diagnoses of any type of thyroid diseases). Asthma, cardiovascular disease, cancer, psychiatric disease, and thyroid disease conditions were determined based on the patient's self-report on admission.

\section{Statistical Analysis}

Obtained data were entered and analyzed using SAS version 9.4. Descriptive data were reported for categorical variables as frequencies with percentages, and for the continuous variables, as mean with standard deviation (SD) and median and interquartile range (IQR) to examine the distribution of study variables among study groups. Chi-square or Fisher's exact test, as appropriate, was utilized to evaluate categorical variables between groups. Continuous variables, if normally distributed, were compared, using Student's $t$-test; if not, the Mann-Whitney
$U$-test (Wilcoxon rank-sum test) was employed. No imputation was performed for all tests, and a $P$-value below 0.05 was deemed statistically significant.

\section{Results}

\section{Study Population Characteristics}

From March 1, 2020, to May 20, 2020, 458 cases infected with COVID-19 were reported and included in the analysis. Characteristics, outcomes, and treatment of included patients are presented by chronic-condition groups in Table 1. The study population was 458 patients: 38 patients were classified as patients without chronic conditions, 324 patients as patients with one chronic condition, and 96 as patients with two or more chronic conditions. The average age for the study population was 38.8 years (SD 12.8). With respect to age, patients aged between 20 and 39 years made up the majority of the study population at $59.4 \%$, followed by those aged between 40 and 59 years at $30.6 \%$,older than 60 at $7.4 \%$, and younger than 20 at $2.6 \%$. Male patients accounted for $86.9 \%$ of the study population. There were $398(86.9 \%)$ males in the study population, most of them with one chronic condition, including 14 (14.3\%) smokers, and the majority of them were among patients with two or more chronic conditions group.

\section{Outcomes}

Among the patients, the average length of hospital stay and time in the ICU were 6.6 days (SD 6.3) and 9.2 days (SD 5.2), respectively, most of them among patients with two or more chronic conditions. The percentage of patients in the entire study population who were admitted to the ICU was $10.2 \%$, while the percentage of patients who needed mechanical ventilation was 9.4\%. Similarly, a statistically greater percentage of patients requiring ICU admission and mechanical ventilation were found among patients with two or more chronic conditions.

\section{Treatment for Patients Infected with COVID-19}

Antibacterial drugs, antimalarial drugs, antithrombotic drugs, and antiviral treatment drugs were the main treatments prescribed to COVID-19 patients. Treatments based on the number of chronic conditions are shown in Table 1. Antibacterial drugs were the most commonly used class overall. Most patients (84.77\%) received Azithromycin $(41.46 \%)$. (see the Table A1 in the appendix) 
Table I Baseline Characteristics, Outcomes and Treatment of 458 Patients Infected with COVID- 19 Stratified by Number of Chronic Conditions

\begin{tabular}{|c|c|c|c|c|c|}
\hline Characteristics & $\begin{array}{l}\text { Total } \\
\text { Patients } \\
(\mathrm{N}=458)\end{array}$ & $\begin{array}{l}\text { Patients without } \\
\text { Chronic Conditions } \\
(\mathrm{N}=38)\end{array}$ & $\begin{array}{l}\text { Patients with One } \\
\text { Chronic Condition } \\
(\mathrm{N}=324)\end{array}$ & $\begin{array}{l}\text { Patients with } \geq 2 \\
\text { Chronic Conditions } \\
(\mathrm{N}=96)\end{array}$ & $P$ value \\
\hline Age, mean (SD), years & $\begin{array}{l}38.82 \\
(I 2.86)\end{array}$ & $37.52(\mid 3.2 I)$ & 37.71 (11.99) & $43.11(14.67)$ & $<0.001$ \\
\hline $\begin{array}{l}\text { Age, years, } \mathbf{n}(\%) \\
\quad<20 \\
20-39 \\
40-59 \\
>60\end{array}$ & $\begin{array}{l}\text { I2 (2.62) } \\
272(59.39) \\
140(30.57) \\
34(7.42)\end{array}$ & $\begin{array}{l}2(5.26) \\
25(65.79) \\
9(23.68) \\
2(5.26)\end{array}$ & $\begin{array}{l}9(2.78) \\
207(63.89) \\
87(26.85) \\
21(6.48)\end{array}$ & $\begin{array}{l}\text { I }(1.04) \\
40(4 I .67) \\
44(45.83) \\
\text { II }(11.46)\end{array}$ & 0.002 \\
\hline $\begin{array}{l}\text { Gender, n (\%) } \\
\text { Female } \\
\text { Male }\end{array}$ & $\begin{array}{l}60(13.1) \\
398(86.9)\end{array}$ & $\begin{array}{l}8(21.05) \\
30(78.95)\end{array}$ & $\begin{array}{l}37(11.42) \\
287(88.58)\end{array}$ & $\begin{array}{l}15(15.63) \\
81(84.38)\end{array}$ & 0.178 \\
\hline $\begin{array}{l}\text { Nationality, n (\%) } \\
\text { Non-Saudi } \\
\text { Saudi }\end{array}$ & $\begin{array}{l}368(80.35) \\
90(19.65)\end{array}$ & $\begin{array}{l}29(76.32) \\
9(23.68)\end{array}$ & $\begin{array}{l}273(84.26) \\
51(15.74)\end{array}$ & $\begin{array}{l}66(68.75) \\
30(31.25)\end{array}$ & 0.002 \\
\hline $\begin{array}{l}\text { Smoker, n (\%) } \\
\text { No } \\
\text { Yes }\end{array}$ & $\begin{array}{l}84(85.7 I) \\
14(14.29)\end{array}$ & $\begin{array}{l}16(100) \\
0(0)\end{array}$ & $\begin{array}{l}49(89.09) \\
6(10.91)\end{array}$ & $\begin{array}{l}19(70.37) \\
8(29.63)\end{array}$ & 0.015 \\
\hline $\begin{array}{l}\text { Any symptoms, n (\%) } \\
\text { No } \\
\text { Yes }\end{array}$ & $\begin{array}{l}50 \text { (11.01) } \\
404 \text { (88.99) }\end{array}$ & $\begin{array}{l}6(15.79) \\
32(84.21)\end{array}$ & $\begin{array}{l}32(10) \\
288(90)\end{array}$ & $\begin{array}{l}12(12.5) \\
84(87.5)\end{array}$ & 0.487 \\
\hline $\begin{array}{l}\text { Outcomes } \\
\text { Length of hospital stay, days, mean (SD) } \\
\text { Time in ICU, days, mean (SD) } \\
\text { ICU admission, } \mathrm{n}(\%) \\
\text { Mechanical ventilation, n (\%) } \\
\text { Discharged, n (\%) } \\
\text { Died, n (\%) }\end{array}$ & $\begin{array}{l}6.57(6.3 \mathrm{I}) \\
9.2 \mathrm{I}(5.19) \\
47(10.26) \\
43(9.43) \\
456(99.56) \\
2(0.44)\end{array}$ & $\begin{array}{l}4.68(4.21) \\
0(0) \\
0(0) \\
2(5.26) \\
179(98.9) \\
2(1.1)\end{array}$ & $\begin{array}{l}5.38(4.96) \\
0.05(0.94) \\
I(0.31) \\
3(0.93) \\
203(100) \\
0(0)\end{array}$ & $\begin{array}{l}\text { II.36(8.45) } \\
4.33(5.74) \\
46(47.92) \\
38(39.58) \\
74(100) \\
0(0)\end{array}$ & $\begin{array}{l}<0.001 \\
<0.001 \\
<0.001 \\
<0.001 \\
0.453 \\
0.453\end{array}$ \\
\hline $\begin{array}{l}\text { Treatment } \\
\text { Antimalaria, n (\%) } \\
\text { Antiviral therapy, n (\%) } \\
\text { Antibacterial, n (\%) } \\
\text { Antithrombotic therapy, n (\%) }\end{array}$ & $\begin{array}{l}92(37.4) \\
10(4.07) \\
153(62.2) \\
91(36.99)\end{array}$ & $\begin{array}{l}6(28.57) \\
0(0) \\
\text { II (52.38) } \\
9(42.86)\end{array}$ & $\begin{array}{l}61(40.4) \\
5(3.31) \\
96(63.58) \\
54(35.76)\end{array}$ & $\begin{array}{l}25(33.78) \\
5(6.76) \\
46(62.16) \\
28(37.84)\end{array}$ & $\begin{array}{l}0.429 \\
0.288 \\
0.611 \\
0.806\end{array}$ \\
\hline
\end{tabular}

\section{Clinical Characteristics}

Reported signs and symptoms for the study population by study groups are shown in Table 2. For the entire study population, fever, dry cough, and dyspnea were the most common symptoms upon admission. Dyspnea was found to be significantly higher among patients with two or more chronic conditions. More than $43 \%$ of patients had a systolic blood pressure of $120-140 \mathrm{~mm} \mathrm{Hg}$, while $69.8 \%$ had their diastolic blood pressure between 90 and $100 \mathrm{~mm}$ Hg. Of patients with two or more chronic conditions, 19.1\% of them had systolic blood pressure over $140 \mathrm{~mm} \mathrm{Hg}$.
There were numerous significant differences in laboratory findings between patients' different groups (Table 2). Lower respiratory rate (mean respiratory rate, 19.1 [SD1.75]) was noticed among patients with one chronic condition. Patients with two or more chronic conditions showed an increased level of platelet counts (median count, 264.5 [SD 102.33] $\times 109 / \mathrm{L})$ and had a reduction in hemoglobin levels (median concentration, $130.9 \mathrm{~g} / \mathrm{L}$ [SD 17.24]) compared to other groups.

In terms of chronic conditions, the most common type of chronic condition was diabetes mellitus, which 
Table 2 Clinical Signs and Symptoms of 458 Patients Infected with COVID-19 Stratified by Number of Chronic Conditions

\begin{tabular}{|c|c|c|c|c|c|}
\hline Signs and Symptoms & $\begin{array}{l}\text { Total } \\
\text { Patients } \\
(\mathrm{N}=458)\end{array}$ & $\begin{array}{l}\text { Patients without } \\
\text { Chronic } \\
\text { Conditions }(\mathrm{N}=38)\end{array}$ & $\begin{array}{l}\text { Patients with One } \\
\text { Chronic Condition } \\
(\mathrm{N}=324)\end{array}$ & $\begin{array}{l}\text { Patients with } \geq 2 \\
\text { Chronic } \\
\text { Conditions }(\mathrm{N}=60)\end{array}$ & $P$ value \\
\hline Fever, n (\%) & 324 (70.74) & $24(63.16)$ & 232 (7I.6) & 68 (70.83) & 0.5563 \\
\hline Dry cough, n (\%) & $277(60.48)$ & $19(50)$ & $192(59.26)$ & $66(68.75)$ & 0.0956 \\
\hline Dyspnea, n (\%) & $128(27.95)$ & $12(31.58)$ & $74(22.84)$ & $42(43.75)$ & 0.0003 \\
\hline Sore throat, n (\%) & $62(13.54)$ & $8(21.05)$ & 45 (1 3.89) & $9(9.38)$ & 0.1931 \\
\hline Diarrhea, n (\%) & $44(9.61)$ & $3(7.89)$ & $29(8.95)$ & $12(12.5)$ & 0.5449 \\
\hline Fatigue, n (\%) & $29(6.33)$ & $4(10.53)$ & $17(5.25)$ & $8(8.33)$ & 0.2984 \\
\hline Vomiting, n (\%) & $23(5.02)$ & $2(5.26)$ & $14(4.32)$ & 7 (7.29) & 0.5028 \\
\hline Runny nose, n (\%) & $17(3.7 \mid)$ & $2(5.26)$ & $10(3.09)$ & $5(5.2 I)$ & 0.5455 \\
\hline Chest pain, n (\%) & $14(3.06)$ & $3(7.89)$ & $9(2.78)$ & $2(2.08)$ & 0.1833 \\
\hline Abdominal pain, n (\%) & II (2.4) & I (2.63) & $8(2.47)$ & $2(2.08)$ & 0.9722 \\
\hline Myalgia, n (\%) & $7(1.53)$ & $0(0)$ & $5(1.54)$ & $2(2.08)$ & 0.6748 \\
\hline Nausea, n (\%) & $7(1.53)$ & $0(0)$ & $6(1.85)$ & I (I.04) & 0.6169 \\
\hline $\begin{array}{l}\text { Systolic blood pressure, } \mathrm{mm} \mathrm{Hg} \text {, } \\
\text { n (\%) }\end{array}$ & & & & & 0.0053 \\
\hline$<100$ & $15(3.6)$ & $2(5.4 I)$ & $6(2.03)$ & 7 (8.33) & \\
\hline $100-119$ & I7I (4I.0I) & $13(35.14)$ & $120(40.54)$ & $38(45.24)$ & \\
\hline $120-140$ & $180(43.17)$ & 18 (48.65) & 139 (46.96) & $23(27.38)$ & \\
\hline$>140$ & 51 (12.23) & $4(10.81)$ & 31 (10.47) & 16 (19.05) & \\
\hline $\begin{array}{l}\text { Diastolic blood pressure, } \mathrm{mm} \mathrm{Hg} \text {, } \\
\text { n (\%) }\end{array}$ & & & & & 0.6357 \\
\hline$<80$ & 291 (69.78) & $22(59.46)$ & 207 (69.93) & $62(73.81)$ & \\
\hline $80-89$ & $86(20.62)$ & I I (29.73) & $59(19.93)$ & 16 (19.05) & \\
\hline $90-100$ & $34(8.15)$ & $3(8.11)$ & $25(8.45)$ & $6(7.14)$ & \\
\hline$>100$ & $6(1.44)$ & I (2.7) & 5 (1.69) & $0(0)$ & \\
\hline Body Temperature, ${ }^{\circ} \mathrm{C}$, mean (SD) & $37.28(0.78)$ & $37.42(0.87)$ & $37.27(0.77)$ & $37.24(0.75)$ & 0.672 \\
\hline $\begin{array}{l}\text { Heart rate, beats per minute (BPM), } \\
\text { mean (SD) }\end{array}$ & $88.72(15.45)$ & $94.23(16.44)$ & $88.26(14.89)$ & $88.23(16.51)$ & 0.453 \\
\hline $\begin{array}{l}\text { Respiratory rate, breaths per minute } \\
\text { (BPM), mean (SD) }\end{array}$ & $19.63(2.98)$ & $19.65(2.52)$ & $19.07(1.75)$ & $2 I .6 I(5 . I I)$ & $<0.001$ \\
\hline $\begin{array}{l}\text { White blood cell count (WBC), } \times 10^{9} / \mathrm{L} \text {, } \\
\text { mean (SD) }\end{array}$ & $6.83(2.94)$ & $6.54(2.37)$ & $6.52(2.42)$ & $7.76(4.10)$ & 0.161 \\
\hline Platelet count (PLT), × $10^{9} / \mathrm{L}$, mean (SD) & $243.13(88.33)$ & $259.48(95.43)$ & $233.27(80.22)$ & $264.46(102.33)$ & 0.026 \\
\hline Hemoglobin (Hgb), g/dl, mean (SD) & $146.45(17.84)$ & |47.58 (14.14) & $152.12(14.77)$ & I $30.86(\mid 7.24)$ & $<0.001$ \\
\hline $\begin{array}{l}\text { International Normalized Ratio (INR), } \\
\text { mean (SD) }\end{array}$ & $\mathrm{I} .02(0.1 \mathrm{I})$ & I.0I (0.07) & $\mathrm{I} .0 \mathrm{I}(0.1 \mathrm{I})$ & $\mathrm{I} .04(0.1 \mathrm{I})$ & 0.067 \\
\hline Creatinine, $\mu \mathrm{mol} / \mathrm{L}$, mean (SD) & $78.71(16.05)$ & $89.96(10.81)$ & $83.01(14.71)$ & $88.03(14.22)$ & 0.672 \\
\hline Sodium (Na), mmol/L, mean (SD) & $|37.5|(3.26)$ & $137.16(3.57)$ & $137.60(2.72)$ & $137.40(4.33)$ & 0.358 \\
\hline Chloride (Cl), mmol/L, mean (SD) & $103.53(3.96)$ & $102.80(5.02)$ & $103.56(3.58)$ & $103.67(4.54)$ & 0.931 \\
\hline
\end{tabular}

accounted for $13.6 \%$ of patients with chronic conditions, followed by hypertension with $10.9 \%$ of the cases, and asthma contributing to $3.5 \%$ of cases (Figure 1).

\section{Discussion}

In this descriptive, cross-sectional, single-center study, we reviewed the electronic medical records of 458 adult patients to assess the clinical characteristics and outcomes of COVID-19 patients.

We found in the study that the majority of study population were adults and older individuals, and the number of chronic conditions appeared to be more among older patients with an age of 40 years or above. In previous study, it was observed that the most common occurrence of COVID-19 was in adult male patients aged 34-59 


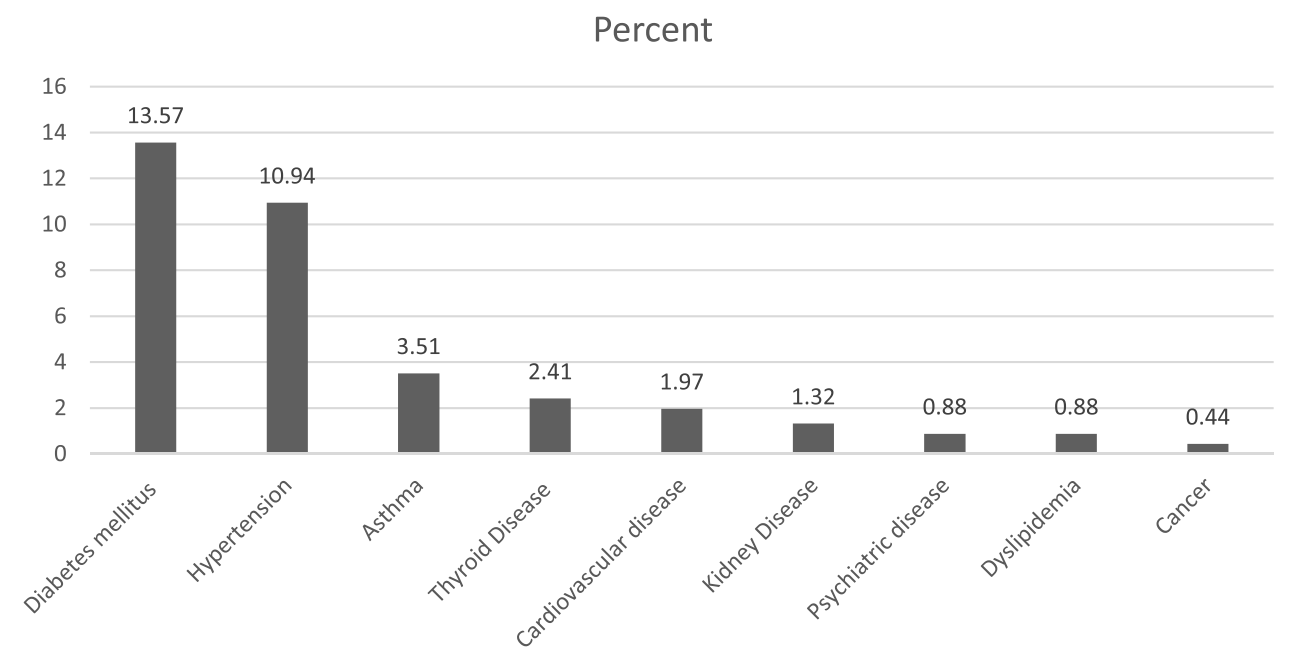

Figure I Percentages of COVID-19 patients with chronic conditions.

years. ${ }^{17}$ It was well documented that older people and patients with chronic conditions are more susceptible to COVID-19 infection. ${ }^{18}$ On the other hand, in our study, we recorded very few cases of COVID-19 in individuals under 20 years of age. The reason may be that they are less likely to get infected or have milder symptoms if infected. Therefore, they might not seek treatment for these cases, which results in lower prevalence and hospitalization of COVID-19 in these age groups.

In our study of COVID-19 patients, we observed an average hospitalization period of 6 to 7 days, whereas, for ICU, it was 9 to 10 days, which is similar to the previously reported studies. ${ }^{19}$ The incubation period for COVID-19 is predicted to be a maximum of 14 days, with a median period of 4 to 5 days from exposure to onset of symptoms. ${ }^{19-21}$ Similar findings have been reported for other patients with COVID-19, where a study showed that $97.5 \%$ of patients infected with COVID-19 would experience symptoms within 11.5 days from infection. ${ }^{21}$ In addition, another study reported median (IQR) 5(3-8.8), 7(3-13.8), 20 (11.8-28), 27 (2-31) respectively for the time (days) from the outbreak of illness to hospital admission, diagnosis, death, and release from hospital. ${ }^{22}$

Similar to an earlier study conducted in China, ${ }^{23}$ our findings strongly suggest that patients with two or more chronic conditions experienced a poorer prognosis. Length of hospital stay and time in the ICU were significantly longer among patients in this group compared to those in other groups. These findings are not surprising, as it has been shown that chronic conditions have been a strong predictor of worse outcomes among COVID-19 patients according to Italian, US, Swedish, and Spanish surveillance findings. ${ }^{24}$

Our data are also in agreement with findings from an observational study that suggests chronic conditions are associated with an increased risk of a more severe infection requiring COVID-19 hospitalization. ${ }^{25}$ We also observed a significant difference among the three groups of patients admitted to ICU who used mechanical ventilation. Of patients with two or more chronic conditions, $47.92 \%$ received ICU admission, whereas $39.6 \%$ received mechanical ventilation. Our findings in this regard are similar to the global estimate percentages. ${ }^{11}$ For yet another study reported chronic disease $(72.2 \%)$ for ICU patients was higher than in non-ICU-admitted patients $(37.3 \%) .{ }^{26}$ Patients who had been referred to the ICU had different underlying conditions. In this study, we recorded only two deaths, and these were reported in patients without chronic conditions. Because the study sample and number of deaths are too small, it is difficult to show any effect of the number of chronic conditions on the mortality rate. However, it was reported that the current reported mortality rate for COVID-19 is about $3.4 \% .{ }^{27} \mathrm{~A}$ recent influenza disease study indicated that the risk of death from COVID-19 for critical patients with comorbidity was higher compared to patients without chronic conditions. ${ }^{28}$ In earlier studies, it has been suggested that the death rate was linked to the older age of patients with COVID-19, SARS-CoV, and MERS. ${ }^{29}$ Therefore, in this critical situation, there are certain responsibilities for health policy makers to implement comprehensive measures to protect these populations. 
In the literature, COVID-19's main symptoms include fever, dry cough, dyspnea, chest pain, fatigue, and myalgia. ${ }^{26,30,31}$ Headache, dizziness, abdominal discomfort, diarrhea, and nausea are also common. ${ }^{26}$ About $75 \%$ of patients had pneumonia bilaterally. ${ }^{32}$ In this study, fever, dry cough, dyspnea, sore throat, diarrhea, fatigue, and vomiting were the most commonly reported symptoms, whereas runny nose, chest pain, abdominal pain, myalgia, and nausea were relatively rare. Similar results were reported in 425 confirmed cases in Wuhan, where patients experienced symptoms like fever, dry cough, myalgia, and fatigue, whereas production of sputum, headaches, hemoptysis, abdominal pain, and diarrhea were found to be less frequent. ${ }^{19}$ In patients with chronic conditions, a significant difference has been reported in dyspnea. It is presumed that individuals with chronic conditions are more prone to severe infection; therefore, it has been suggested that the initial onset of dyspnea may indicate a poor prognosis. ${ }^{33}$ Non-respiratory symptoms such as palpitation, diarrhea, or headache occasionally appeared before respiratory symptoms. The prevalence of asymptomatic infection cases is yet to be established since most of the initially asymptomatic infections eventually become symptomatic.

Although platelet counts for all patients groups are within the normal level (between 150 and $400 \times 10^{9} / \mathrm{L}$ ), patients with two or more chronic conditions showed increased platelet counts compared to other groups which can be attributed to their severity of the infection. ${ }^{34}$ Similarly, Hemoglobin means for all groups are within the normal level in varied proportions. Patients with two or more chronic conditions presented with a lower hemoglobin level. It was reported that the low hemoglobin value was found to be significantly correlated to the severity COVID-19 infection. ${ }^{35}$

The most common comorbidities were diabetes mellitus, followed by hypertension and asthma. Our findings are in line with other studies from China and Italy of COVID19 infected patients with at least one chronic condition. Among all these cases, the most widely identified diseases are diabetes mellitus (10\%), chronic lung disease (90\%), and cardiovascular disease (9\%). ${ }^{4}$ It suggests that COVID19 patients with risk factors and underlying health conditions, including diabetes mellitus, hypertension, coronary artery disease, COPD, cerebrovascular disease, and chronic renal disease, are at an elevated chance of severe illness or COVID-19 mortality. ${ }^{20}$ Clinical characteristics of 41 patients confirmed to have COVID-19 were reported by a previous study. Among those patients, $32 \%$ were found to be critical as they were diabetic or hypertensive or had cardiovascular and chronic obstructive lung diseases. $^{3}$ The evaluation of the prevalence of these chronic conditions is the basis for the mitigation of complications of COVID-19.

No effective COVID-19 vaccine or antiviral treatment is currently available. However, the efficacy and safety of various drugs given to patients with COVID-19 are currently being tested in randomized multicenter controlled clinical trials. In our study, mostly antibacterial, antimalarial, and antithrombotic drugs were used, and the least frequently used drugs were antivirals. However, COVID19 patients may have been treated with antiviral medications paired with clinical antibiotics. ${ }^{31}$ Finally, no strong evidence exists for the significant improvement of clinical outcomes of COVID-19 patients who were prescribed antivirals. Therefore, disease management adheres primarily to the WHO guidelines for the severity of the disease.

Most countries have implemented quarantine and advised physical distancing in order to limit exposure of people with chronic diseases. However, there is concern that people with chronic illnesses may have distorted perceptions of risk of serious COVID-19 disease and therefore may take precautionary attitudes. ${ }^{36}$ Thus, the use of effective actions to deter future infections can be improved by targeted educational initiatives.

Our analyses may have been affected by several limitations. The data was collected from a single hospital in Riyadh, Saudi Arabia; hence, the clinical courses and outcomes cannot be fully extrapolated to the whole population. In addition, the study population may differ from other populations in terms of their culture, prevalence of different clinical characteristics, and chronic conditions, as well as their access to high quality medical service. Second, $80.3 \%$ of the study population were non-Saudi, who are known to have a different living style and limited resources; hence, the results may not reflect those for the whole population. Finally, incomplete patient data regarding patient history, laboratory findings, and symptoms could modify the narrative.

\section{Conclusion}

The findings of this study revealed a longer hospital stay, longer time in the ICU, a higher probability of ICU admission, and the urgent need for mechanical ventilation among patients with more chronic conditions compared to other groups. Thus, better preventive and treatment 
measures should be used for these patients. The results in the present study will help to predict the prognosis of COVID-19 chronic disease patients, especially recognizing those patients with a greater risk of significant adverse outcomes of COVID-19.

\section{Abbreviations}

COVID-19, coronavirus disease 2019; MERS-CoV, Middle East Respiratory Syndrome Coronavirus; ICU, Intensive Care Unit; WHO, World Health Organization; KSA, Kingdom of Saudi Arabia; STROBE, STrengthening the Reporting of OBservational studies in Epidemiology; PMAH, Prince Mohammed bin Abdul Aziz hospital; BMI, body mass index; HbA1c, Hemoglobin A1c; UACR, urinary albumin creatinine ratio; eGFR, glomerular filtration rate; LDL-C, Low-density lipoprotein cholesterol; HDL-C, high-density lipoprotein cholesterol; SD, standard deviation; IQR, interquartile range.

\section{Data Sharing Statement}

The datasets used and/or analyzed during the current study are available from the corresponding author on reasonable request.

\section{Ethics Approval and Consent-to- Participate}

The study protocol and study methodology were approved by the Ministry of Health's Institutional Review Board (IRB). The permissions from the Ministry of Health $(\mathrm{MoH})$ as well as the hospital management were obtained to conduct this study.

\section{Acknowledgments}

The authors express their gratitude to the Saudi Association for Scientific Research (SASR) for the logistic support they provided during the project.

\section{Author Contributions}

All authors made a significant contribution to the work reported, whether that is in the conception, study design, execution, acquisition of data, analysis and interpretation, or in all these areas; took part in drafting, revising or critically reviewing the article; gave final approval of the version to be published; have agreed on the journal to which the article has been submitted; and agree to be accountable for all aspects of the work.

\section{Funding}

This project was supported by the Deanship of Scientific Research at Prince Sattam bin Abdulaziz University.

\section{Disclosure}

The authors have no conflicts of interest to declare.

\section{References}

1. Lee A. Wuhan novel coronavirus (COVID-19): why global control is challenging? Public Health. 2020;179:A1. doi:10.1016/j. puhe.2020.02.001

2. Yang L, Liu J, Zhang R, et al. Epidemiological and clinical features of 200 hospitalized patients with corona virus disease 2019 outside Wuhan, China: a descriptive study [published online ahead of print, 2020 May 26]. J Clin Virol. 2020;129:104475. doi:10.1016/j. jev.2020.104475

3. Huang C, Wang Y, Li X, et al. Clinical features of patients infected with 2019 novel coronavirus in Wuhan, China. Lancet. 2020;395 (10223):497-506. doi:10.1016/S0140-6736(20)30183-5

4. Chow N, Fleming-Dutra K, Gierke R; CDC COVID-19 Response Team. Preliminary estimates of the prevalence of selected underlying health conditions among patients with Coronavirus Disease 2019 United States, February 12-March 28, 2020. MMWR Morb Mortal Wkly Rep. 2020;69(13):382-386. doi:10.15585/mmwr.mm6913e2

5. Barry M, Ghonem L, Alsharidi A, et al. Coronavirus Disease-2019 Pandemic in the Kingdom of Saudi Arabia: mitigation measures and hospital preparedness. J Nat Sci Med. 2020;3(3):155-158.

6. Barry M, Al Amri M, Memish ZA. COVID-19 in the shadows of MERS-CoV in the Kingdom of Saudi Arabia. $J$ Epidemiol Glob Health. 2020;10(1):1-3. doi:10.2991/jegh.k.200218.003

7. Al Otaibi AM, Kattan WM, Nabil AM. The impact of Saudi (CBAHI) accreditation on enhancing patient safety and improvingthe quality of care indicators. Prensa Med Argent. 2020;106:3.

8. Barry M, Ghonem L, Alsharidi A, et al. Coronavirus Disease 2019 (COVID-19) pandemic in the Kingdom of Saudi Arabia: mitigation measures and hospitals preparedness. J Nat Sci Med. 2020;1.

9. Al-Mandhari A, Samhouri D, Abubakar A, Brennan R. Coronavirus Disease 2019 outbreak: preparedness and readiness of countries in the Eastern Mediterranean Region. East Mediterr Health J. 2020;26 (2):136-137. doi:10.26719/2020.26.2.136

10. Thng ZX, De Smet MD, Lee CS, et al. COVID-19 and immunosuppression: a review of current clinical experiences and implications for ophthalmology patients taking immunosuppressive drugs. $\mathrm{Br}$ $J$ Ophthalmol. 2020;bjophthalmol-2020-316586. doi:10.1136/ bjophthalmol-2020-316586.

11. Alsofayan YM, Althunayyan SM, Khan AA, Hakawi AM, Assiri AM. Clinical characteristics of COVID-19 in Saudi Arabia: a national retrospective study. J Infect Public Health. 2020;13 (7):920-925. doi:10.1016/j.jiph.2020.05.026

12. Bridgewood C, Damiani G, Sharif K, et al. Rationale for evaluating PDE4 inhibition for mitigating against severe inflammation in COVID-19 Pneumonia and beyond. Isr Med Assoc J. 2020;22 (6):335-339.

13. Centers for Disease Control and Prevention (US); National Center for Chronic Disease Prevention and Health Promotion (US); Office on Smoking and Health (US). How tobacco smoke causes disease: the biology and behavioral basis for smoking-attributable disease: a report of the surgeon General. Atlanta (GA): centers for disease control and prevention (US); 2010. Available from: https://www.ncbi.nlm.nih.gov/books/ NBK53017/. Accessed June 17, 2020. 
14. NCD Risk Factor Collaboration (NCD-RisC). Worldwide trends in body-mass index, underweight, overweight, and obesity from 1975 to 2016: a pooled analysis of 2416 population-based measurement studies in 128.9 million children, adolescents, and adults. Lancet 2017;390(10113):2627-2642. doi:10.1016/S0140-6736(17)32129-3.

15. Guideline of American Diabetes Association. Standards of medical care in diabetes-2015: summary of revisions. Diabetes Care. 2015; (38 Suppl):S4. doi:10.2337/dc15-S003

16. Son JS, Choi S, Lee G, et al. Blood pressure change from normal to 2017 ACC/AHA defined stage 1 hypertension and cardiovascular risk. J Clin Med. 2019;8(6):820. doi:10.3390/jcm8060820

17. Chang D, Lin M, Wei L, et al. Epidemiologic and clinical characteristics of Novel Coronavirus infections involving 13 patients outside Wuhan, China. JAMA. 2020;323(11):1092-1093. doi:10.1001/jama. 2020.1623

18. Zhang JJ, Dong X, Cao YY, et al. Clinical characteristics of 140 patients infected with SARS-CoV-2 in Wuhan, China. Allergy. 2020;75(7):1730-1741. doi:10.1111/all.14238

19. Li Q, Guan X, Wu P, et al. Early transmission dynamics in Wuhan, China, of Novel Coronavirus-infected Pneumonia. $N$ Engl J Med. 2020;382(13):1199-1207. doi:10.1056/NEJMoa2001316

20. Guan WJ, Ni ZY, Hu Y, et al. Clinical characteristics of Coronavirus Disease 2019 in China. N Engl J Med. 2020;382(18):1708-1720. doi:10.1056/NEJMoa2002032

21. Lauer SA, Grantz KH, Bi Q, et al. The incubation period of Coronavirus Disease 2019 (COVID-19) from publicly reported confirmed cases: estimation and application. Ann Intern Med. 2020;172 (9):577-582. doi:10.7326/M20-0504

22. Saad M, Omrani AS, Baig K, et al. Clinical aspects and outcomes of 70 patients with Middle East respiratory syndrome coronavirus infection: a single-center experience in Saudi Arabia. Int J Infect Dis. 2014;29:301-306. doi:10.1016/j.ijid.2014.09.003

23. Guan WJ, Liang WH, Zhao Y, et al. Comorbidity and its impact on 1590 patients with COVID-19 in China: a nationwide analysis. Eur Respir J. 2020;55(5):2000547. doi:10.1183/13993003.00547-2020

24. Eurosurveillance Editorial Team. Updated rapid risk assessment from ECDC on coronavirus disease 2019 (COVID-19) pandemic: increased transmission in the EU/EEA and the UK. Euro Surveill. 2020;25 (12):2003121. doi:10.2807/1560-7917.ES.2020.25.12.200326.

25. Montero F, Martínez-Barrio J, Serrano-Benavente B, et al. Coronavirus disease 2019 (COVID-19) in autoimmune and inflammatory conditions: clinical characteristics of poor outcomes. Rheumatol Int. 2020;1-6.
26. Wang $\mathrm{D}, \mathrm{Hu} \mathrm{B}, \mathrm{Hu} \mathrm{C}$, et al. Clinical characteristics of 138 hospitalized patients with 2019 Novel Coronavirus-infected Pneumonia in Wuhan, China. JAMA. 2020;323(11):1061-1069. doi:10.1001/jama. 2020.1585

27. Sohrabi C, Alsafi Z, O'Neill N, et al. World Health Organization declares global emergency: a review of the 2019 novel coronavirus (COVID-19). Int $J$ Surg. 2020;76:71-76. doi:10.1016/j.ijsu.20 20.02.034

28. Yang J, Zheng Y, Gou X, et al. Prevalence of comorbidities and its effects in patients infected with SARS-CoV-2: a systematic review and meta-analysis. Int $J$ Infect Dis. 2020;94:91-95. doi:10.1016/j. ijid.2020.03.017

29. Zhou F, Yu T, Du R, et al. Clinical course and risk factors for mortality of adult inpatients with COVID-19 in Wuhan, China: a retrospective cohort study. Lancet. 2020;395(10229):1054-1062. doi:10.1016/S0140-6736(20)30566-3

30. Harapan H, Itoh N, Yufika A, et al. Coronavirus disease 2019 (COVID-19): a literature review. J Infect Public Health. 2020;13 (5):667-673. doi:10.1016/j.jiph.2020.03.019

31. Zhu N, Zhang D, Wang W, et al. A Novel Coronavirus from patients with Pneumonia in China, 2019. $N$ Engl J Med. 2020;382 (8):727-733. doi:10.1056/NEJMoa2001017

32. Chen N, Zhou M, Dong X, et al. Epidemiological and clinical characteristics of 99 cases of 2019 novel coronavirus pneumonia in Wuhan, China: a descriptive study. Lancet. 2020;395 (10223):507-513. doi:10.1016/S0140-6736(20)30211-7

33. Zhang J, Wang X, Jia X, et al. Risk factors for disease severity, unimprovement, and mortality in COVID-19 patients in Wuhan, China. Clin Microbiol Infect. 2020;26(6):767-772. doi:10.1016/j. cmi.2020.04.012

34. Qiu J, Ma J, Zhang S, Han J, Liu S. Promoting platelets is a therapeutic option to combat severe viral infection of the lung. Blood Adv. 2020;4(8):1640-1642. doi:10.1182/bloodadvances.2020 001669

35. Lippi G, Mattiuzzi C. Hemoglobin value may be decreased in patients with severe coronavirus disease 2019. Hematol Transfus Cell Ther. 2020;42(2):116-117. doi:10.1016/j.htct.2020.03.001

36. Tran VT, Ravaud P. COVID-19-related perceptions, context and attitudes of adults with chronic conditions: results from a crosssectional survey nested in the ComPaRe e-cohort. PLoS One. 2020;15(8):e0237296.
Journal of Multidisciplinary Healthcare

\section{Publish your work in this journal}

The Journal of Multidisciplinary Healthcare is an international, peerreviewed open-access journal that aims to represent and publish research in healthcare areas delivered by practitioners of different disciplines. This includes studies and reviews conducted by multidisciplinary teams as well as research which evaluates the results or conduct of such teams or healthcare processes in general. The journal covers a very wide range of areas and welcomes submissions from practitioners at all levels, from all over the world. The manuscript management system is completely online and includes a very quick and fair peer-review system. Visit http://www.dovepress.com/testimonials. php to read real quotes from published authors. 